\title{
The Potential For Economic Growth And Carbon Dioxide Emissions Reduction: Using Input-Output Framework
}

\author{
Lihao Sun ${ }^{1, a}$, Yuxiang Shen ${ }^{2, b}$ \\ ${ }^{1}$ Shanghai World Foreign Language Academy, Shanghai, China \\ ${ }^{2}$ Shanghai World Foreign Language Academy, Shanghai, China
}

\begin{abstract}
As people's living standards continue to ameliorate, people become more and more demanding of the status of eco-environment, and carbon emissions are a key factor affecting the eco-environment. We analyze the carbon emissions intensity and carbon emissions potential of different sectors in China based on the input-output model. The results show that the sector of Production and Supply of Electric Power and Heat Power has the highest embodied carbon emissions intensity because the sector provides the country with necessary electricity and heat power for its economic growth. In addition, this paper determines the key carbon emissions sectors using elasticity method, and the results show that Construction is the most influential carbon emissions sector in the future. By restricting key carbon emissions sectors and encouraging the non-key carbon emissions sectors, we can take into account both economic development and carbon emissions reduction with the multi-objective model. The results show that under the present economic scale of China, carbon emissions can decrease from 11591 million ton to 11011 million ton, with a difference of 580 million ton. This indicates that with the assurance of present economic growth, we can achieve the goal of reducing carbon emissions by adjusting the economic structure. Based on results of this paper, we have also made recommendations for adjusting the economic structure to achieve emission reduction targets.
\end{abstract}

\section{Introduction}

With the reform and opening-up policies, China's economy boosted; people's lives have become much better and more affluent. However, due to the fallen behind industrial development concept at the beginning of reforming and opening up, the industrial development at that time brought great damage to the environment, which greatly affected the harmonious relationship between human beings and the nature while also constraining future economic development. As chairman Xi Jinping once said, "Lucid waters and lush mountains are invaluable assets," we cannot afford the sacrifice of environment for mere economic development. Therefore, the research question of how to realize sustainable economic development while maintaining the sustainability is of vital importance.

Global warming is a major problem in contemporary eco-environment. As global temperature keeps skyrocketing, global warming will certainly have a number of negative impacts on different animal species. Examples of such negative impacts include sea level rising, abnormal migration of polar bears, etc. More specifically, the main cause of global warming is the overemission of greenhouse gases. Energy saving and emissions reduction are major measures to solve most of the environmental problems faced by China nowadays. In
2009 United Nations Climate Change conference in Copenhagen, Denmark, ministers and officials from 192 countries established an ambitious global climate agreement unanimously for 2012 to 2020; in 2018 Beijing World Economic and Environmental Conference, conference chairman Zhongli Ding mentioned, "China ought to put into effect eco-environmental policies and measures, and use laws to restrain the negative impacts that economic development has on eco-environment." From this perspective, the world, especially China, has attached great importance to the problem of carbon emission, so China should immediately set forth a program of reforms to implement reasonable and effective emissions reduction. However, carbon emissions are indispensable in industrial development; thus, merely reducing carbon emissions will restrict the development of industrial production and even the whole economy. Therefore, in order to take into account both economic development and environment and reconcile as much as possible the negative impacts that economic development has on the environment, the realization of green economic development is imperative under such circumstances.

aslhleo@163.com, btwofb@sina.com 


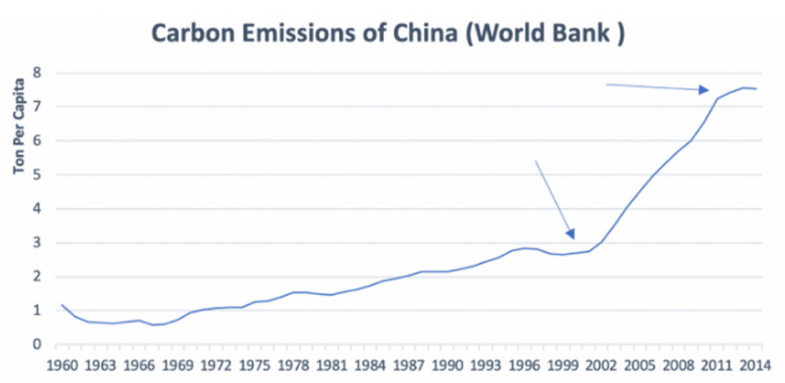

Figure 1. trend of carbon emissions per capita in China (World Bank)

In order to better balance the relationship between economic development and eco-environment, this research will mainly use the input-output analysis framework. Leontief creatively proposed the method of input-output analysis in 1940s, which can show the mutual dependence of the inputs and outputs inside an economic system. Based on this methodology, the relationship between the environment and the sectors' outputs can be drawn by adding some environmental factors or some index of pollutants (Yan and Yang, 2009). Thus, by using the input-output analysis framework, this research will comprehensively consider the relation between eco-environment and economic development, analyze the potential of reduction of China's carbon emissions, and provide suggestions for the realization of low-carbon development.

Therefore, the innovation of this research program is shown as follows. First, by using elasticity calculation, we can derive the key departments and analyze their effects on carbon emissions. Second, based on input-output analysis framework, we build a multi-objective programming model and comprehensively consider economic development and carbon emissions in order to provide suggestions for Chinese emission-reducing path. Third, we simulate how future changes in outputs of different departments affect carbon emissions.

\section{Input-output model and data sources}

\subsection{Reasons for using the input-output model}

Input-output model is a quantitative economic model that represents the interdependencies between different sectors of a national economy or different regional economies (Leontief, 1971). By building economic model, we would like to analyze carbon emissions of different sectors in order to reach a conclusion of how to make lowest carbon emissions while also maintaining the trend of economic development. Generally speaking, sectors that involve burning of fossil fuels mainly include Electric Power, Gas and Water Production and Supply sector, Mining sector, Metal Smelting sector, and other basic sectors. Other sectors do not directly consume fossil fuels, not meaning that they do not have any carbon emissions. For instance, Electric Power, Gas and Water Production and Supply sector generates electricity by consuming coal and natural gas, and then supplies other sectors with such electricity. By consuming electricity, other sectors such as service sector makes its connection during its production to Electric Power, Gas and Water Production and Supply sector, which means that the service sector should be responsible for the carbon emissions due to its consumption of electricity. In other words, many sectors in national economy, such as service sector, does not directly consume fossil fuel but indirectly emits carbon by consuming fossil fuel through electricity generation sector. Because of such relation, we adopt input-output model to describe the inner economic relation between them. On the other hand, Leontief proposed the input-output model in 1936; after decades, it has been widely used in research of national economic accounting and plays a key role in analysis of interregional connection, energy consumption, environment input-output, etc. The framework of inputoutput model is mature (Miller,1966; Ang, 1995; Itoh and Nakata, 2004). We will comprehensively consider the characteristic of eco-environment-friendly high-quality development and innovatively complete the research on top of previous research.

\subsection{Main Research Content}

While considering the way to balance eco-environment and economic development, this paper builds model on the basis of the input-output model in order to provide solutions to several questions as follows.

First, the calculation of carbon emissions intensity of national sectors and determination of key carbon emissions sectors through elasticity. In China's division of sectors, each sector consumes different amount of fossil fuel and carbon emissions. Therefore, determining key carbon emissions sectors, i.e. high-energy-consuming and high-carbon-emitting sectors, is very meaningful. In the future economic programming process, we can reduce the ratio of such high-carbon-emitting sectors in order to facilitate the reduction on national carbon emissions, better balancing economic development and the sustainability of eco-environment.

Second, analysis of carbon emissions reduction potential under given conditions combing with objective programming model. So far, China's economic structure is under adjustment - transforming from the original mere growth-demanding economic development to highquality sustainable economic development. Thus, by determining the key carbon emissions sectors, analysis of China's carbon emissions reduction potential appears to be extremely important.

\subsection{Data Source}

TABLE I. DATA SOURCE

\begin{tabular}{|l|l|}
\hline Data Name & Data Source \\
\hline China Carbon & \\
Emissions & World Bank \\
Yearbook & \\
\hline
\end{tabular}




\begin{tabular}{|l|l|}
\hline $\begin{array}{l}\text { Input-output } \\
\text { Table }\end{array}$ & $\begin{array}{l}\text { National Bureau of Statistics } \\
\text { of the People's Republic of } \\
\text { China }\end{array}$ \\
\hline $\begin{array}{l}\text { Industry- } \\
\text { decomposed } \\
\text { Energy } \\
\begin{array}{l}\text { Consumption } \\
\text { table }\end{array}\end{array}$ & $\begin{array}{l}\text { National Energy } \\
\text { Administration of the } \\
\text { People's Republic of China }\end{array}$ \\
\hline
\end{tabular}

\section{Input-output model}

\subsection{The basic framework of the input-output model}

Leontief developed the input-output model in year 1936 to describe the relation between production input and distribution of products between sectors in an economic system (Leontief, 1936). Based on Leontief's research, scholars introduced elements such as the consumption of energy, and expanded the basic input-output model into the energy input-output model (Miller and Blair, 2014). This section will first introduce the basic input-output model. The form of the input-output model is shown as below:

TABLE II. FORM OF INPUT-OUTPUT MODEL

\begin{tabular}{|c|c|c|c|c|c|c|c|c|c|}
\hline \multirow{2}{*}{ Output } & \multicolumn{7}{|c|}{ Intermediate use } & \multirow{2}{*}{$\begin{array}{c}\text { Final Demand } \\
\text { Sum }\end{array}$} & \multirow{2}{*}{$\begin{array}{c}\text { Total Output } \\
\text { Total } \\
\end{array}$} \\
\hline & Sector & 1 & $\ldots$ & $j$ & $\ldots$ & $n$ & Sum & & \\
\hline \multirow{6}{*}{$\begin{array}{c}\text { Intermediate } \\
\text { Input }\end{array}$} & 1 & $x_{I I}$ & & & & & $x_{l}$ & $Y_{l}$ & $X_{i}$ \\
\hline & $\ldots$ & & & & & & $\ldots$ & $\ldots$ & $\ldots$ \\
\hline & $i$ & & & $x_{i j}$ & & & $x_{i}$ & $Y_{i}$ & $X_{i}$ \\
\hline & $\ldots$ & & & & & & $\ldots$ & $\ldots$ & $\ldots$ \\
\hline & $n$ & & & & & $x_{n n}$ & $x_{n}$ & $Y_{n}$ & $X_{n}$ \\
\hline & Sum & $x_{.1}$ & & $x_{j}$ & & $x_{\cdot n}$ & & & \\
\hline \multicolumn{10}{|l|}{$\begin{array}{l}\text { Value- } \\
\text { Added }\end{array}$} \\
\hline Total Input & Total & $X_{I}$ & $\ldots$ & $X_{j}$ & $\ldots$ & $X_{n}$ & & & \\
\hline
\end{tabular}

$x_{i j}$ represents the consumption of the sector $i$ 's output by sector $j$, i.e. the consumption of products from other sectors during the production process of sector $j . Y_{i}$ represents the final demand of sector $i$, which is the part that is not consumed during the production process; this part is reflected as consumption, investment and export; it is also the source of the GDP Accounting by Expenditure Method. $X_{i}$ represents total output of sector $i$, including intermediate use and final demand. The sector's total output here is equal to the total input. The basic relationship of the input-output table, i.e. total output is equal to the sum of the intermediate output and final demand, can be shown as below:

$$
\left\{\begin{array}{c}
x_{11}+x_{12}+\cdots+x_{1 n}+Y_{1}=X_{1} \\
\cdots \\
x_{i 1}+x_{i 2}+\cdots+x_{i n}+Y_{i}=X_{i} \\
\cdots \\
x_{n 1}+x_{n 2}+\cdots+x_{n n}+Y_{n}=X_{n}
\end{array}\right.
$$

The direct input coefficient is defined to be: $a_{i j}=\frac{x_{i j}}{X_{j}}$.

The equation above represents the consumption of sector $i$ 's products by sector $j$ 's output per unit. In other words, it is the percentage of sector $i$ 's product in the total output of sector $j$. Through direct input coefficient, the relationship above between the total output, intermediate output, and final demand can be rearranged into:

$$
\left\{\begin{array}{c}
a_{11} X_{1}+a_{12} X_{2}+\cdots+a_{1 n} X_{n}+Y_{1}=X_{1} \\
\cdots \\
a_{i 1} X_{1}+a_{i 2} X_{2}+\cdots+a_{i n} X_{n}+Y_{i}=X_{i} \\
\cdots \\
a_{n 1} X_{1}+a_{n 2} X_{2}+\cdots+a_{n n} X_{n}+Y_{n}=X_{n}
\end{array}\right.
$$

According to Leontief's input-output model, the formula above can be expressed in the form of matrix:

$$
\mathbf{A X}+\mathbf{Y}=\mathbf{X}
$$

Express the total output with a function about final output:

$$
\mathbf{X}=(\mathbf{I}-\mathbf{A})^{-\mathbf{1}} \mathbf{Y}
$$

$(\mathbf{I}-\mathbf{A})^{-\mathbf{1}}$ denotes the matrix of total demand coefficient (Leontief inverse matrix), where $\mathbf{X}$ represents total output and $\mathbf{Y}$ represents the final demand. Through the process above, we can demonstrate the basic framework of the input-output model. The next step is to calculate each sector's $\mathrm{CO}_{2}$ emissions by extending this framework.

\subsection{The prediction of the carbon dioxide emissions}

This research defines the emission intensity of carbon dioxide to be the emission of $\mathrm{CO}_{2}$ per unit output. Due to lack of imported products' carbon emission data, this paper hypothesized that the imported products have the same potential carbon emission intensity with the domestic products. This paper mainly uses standards and methods of compilation for greenhouse gases in Guidelines for Provincial Greenhouse Gas Inventory Compilation published in year 2011 for reference. Combined with the energy consumption data in our country's Energy Statistical Yearbook, we categorized the energy sources to raw coal, coke and other six sources. The $\mathrm{CO}_{2}$ emissions of each sector and its emission intensity is calculated as below:

$$
\begin{gathered}
E_{i}=\sum_{j=1}^{8} N C V_{i j} \times E F_{I J} \times O_{i j} \times \frac{44}{12} \times C_{i j} \\
f_{i}^{d}=\frac{E_{i}}{X_{i}}
\end{gathered}
$$

$E_{i}$ represents sector $i$ 's direct total carbon emissions; $f_{i}^{d}$ is sector $i$ 's direct $\mathrm{CO}_{2}$ intensity; $F D_{i}$ is the final product of sector $i ; N C V_{i j}$ represents average low calorific value per unit fuel $j$ (calorific value that is close to the heat produced when burning); $E F_{i j}$ represents carbon content per unit calorific value of sector $i ; O_{i j}$ represents fuel $j$ 's carbon oxidation rate. Different kinds of energy sources' relevant indices are shown as below: 
TABLE III. $\quad \mathrm{CO}_{2}$ INDEX OF FOSSIL FUELS

\begin{tabular}{|c|c|c|c|c|}
\hline $\begin{array}{l}\text { Name of the } \\
\text { energy source }\end{array}$ & $\begin{array}{c}\text { Average net } \\
\text { calorific } \\
\text { power } \\
(\mathrm{KJ} / \mathrm{Kg} ; \\
\left.\mathrm{KJ} / \mathrm{m}^{3}\right)\end{array}$ & $\begin{array}{l}\text { Carbon content per } \\
\text { average calorific } \\
\text { value } \\
\left(10^{-6} \mathrm{Kg}-\mathrm{C} / \mathrm{KJ}\right)\end{array}$ & $\begin{array}{c}\text { Carbon } \\
\text { oxidation rate }\end{array}$ & $\begin{array}{l}\text { coefficient of } \mathrm{CO}_{2} \\
\text { emissions } \\
\left(\mathrm{Kg}-\mathrm{CO}_{2} / \mathrm{Kg} ; \mathrm{Kg} \text { - }\right. \\
\left.\mathrm{CO}_{2} / \mathrm{m}^{3}\right)\end{array}$ \\
\hline Raw coal & 20908 & 26.37 & 0.94 & 1.9003 \\
\hline Coke & 28435 & 29.42 & 0.93 & 2.8604 \\
\hline Crude oil & 41816 & 20.08 & 0.98 & 3.0202 \\
\hline Gasoline & 43070 & 18.9 & 0.98 & 2.9251 \\
\hline Kerosene & 43070 & 19.6 & 0.98 & 3.0179 \\
\hline Diesel oil & 42652 & 20.20 & 0.98 & 3.0959 \\
\hline Fuel oil & 41816 & 21.1 & 0.98 & 3.1705 \\
\hline Natural gas & 38931 & 15.32 & 0.99 & 2.165 \\
\hline
\end{tabular}

The right most column in the table above represents the mass of $\mathrm{CO}_{2}$ produced by per unit mass of fuel, which is the coefficient of $\mathrm{CO}_{2}$ emission. The total emission of $\mathrm{CO}_{2}$ by sector $i$ can be expressed as the product of sector $i$ 's fuel consumption and the coefficient of $\mathrm{CO}_{2}$ emission. The value calculated using the data above is about 10923.690 million tons, which is close to the value provided by the World Bank. With small uncertainty relative to the true value, the result of the calculation can be adopted.

\subsection{Sector Aggregation}

Because the sector division of the input-output table made by National Bureau of Statistics of China is different from the China Energy Statistical Yearbook made by China Energy Administration, we need to combine the sectors in order to achieve correspondence between the sectors of the two tables ( $\mathrm{Su}$ et al., 2010). Assume that $G\left(g_{i j}\right)_{m \cdot n}$ is the simple grouping matrix, with each column equaling to 1. $Z, Y$ and $X$ represent the intermediate input-output matrix, final output matrix, and total output matrix respectively. For instance, if we have 3 sectors and want to aggregate Sector 2 and Sector 3, the whole procedure is shown as follows:

$$
\begin{aligned}
G=\left(\begin{array}{lll}
1 & 0 & 0 \\
0 & 1 & 1
\end{array}\right), Z= & \left(\begin{array}{lll}
x_{11} & x_{12} & x_{13} \\
x_{21} & x_{22} & x_{23} \\
x_{31} & x_{32} & x_{33}
\end{array}\right), Y=\left(\begin{array}{l}
Y_{1} \\
Y_{2} \\
Y_{3}
\end{array}\right), X= \\
& \left(\begin{array}{l}
X_{1} \\
X_{2} \\
X_{3}
\end{array}\right)
\end{aligned}
$$

By multiplying $G$ with other matrices, we can aggregate Sector 2 and Sector 3.

$$
\begin{gathered}
G Z G^{\prime}=\left(\begin{array}{cc}
x_{11} & x_{12}+x_{13} \\
x_{21}+x_{31} & x_{22}+x_{32}+x_{23}+x_{33}
\end{array}\right) \\
G Y=\left(\begin{array}{c}
Y_{1} \\
Y_{2}+Y_{3}
\end{array}\right), G X=\left(\begin{array}{c}
X_{1} \\
x_{2}+X_{3}
\end{array}\right)
\end{gathered}
$$

By multiplying the grouping matrix, we reached the purpose of sector aggregation. And hence, we could calculate the carbon emissions though different sector division. In this case, by combining the sectors, we can achieve correspondence between the sectors of two tables through the equations shown below.

$$
Z^{*}=G Z G^{\prime}, Y^{*}=G Y, X^{*}=G X
$$

\subsection{Adjustment to the direct consumption matrix}

In the input-output analysis, we need to distinguish local domestic goods and imported goods. For foreign imported goods, due to the fact that the production of such goods does not take place in China, this portion of the goods will not contribute to the carbon emissions of China. However, because of the effects of compiling and other factors, the input-output table announced by National Bureau of Statistics is competitive input-output table, i.e. the intermediate use and final demand parts of the table do not separate domestic and imported goods. Thus, direct use of data from the input-output table will cause misleading evaluation of related numerical value, which is not reasonable (Chang, 2015). This part of our paper will focus on the adjustment of foreign imported goods, making intermediate use and final demand to include only local domestic goods.

If we denote $s_{i}$ as the import percentage of $i$ th sector, the adjustment process is shown by the following equation:

$$
s_{i}=\frac{m_{i}}{X_{i}+m_{i}-e_{i}}
$$

Where $X_{i}$ is the total output of $i$ th department, $m_{i}$ is the total import of $i$ th sector. We use this equation because in the input-output table, each value of intermediate use or final output (except for the export) is a summation of local domestic goods and foreign imported goods. Therefore, by using this way, we can exclude the portion of foreign imported goods from inputoutput data, and then the data set can be more reasonably used to calculate the carbon emissions of each sector in a much more accurate manner.

The new direct consumption coefficient matrix and final demand matrix can be expressed as

$$
\mathbf{A}_{\mathbf{d}}=(\mathbf{I}-\hat{\mathbf{s}}) \times \mathbf{A}, \mathbf{Y}_{\mathbf{d}}=\left[(\mathbf{I}-\hat{\mathbf{s}}) \times \mathbf{Y}_{-\mathbf{e}} \mathbf{e}\right]
$$

In this paper, “^” represents diagonal matrix, i.e. $\hat{\mathbf{s}}=$ $\left[\begin{array}{ccc}s_{1} & 0 & 0 \\ 0 & \ddots & 0 \\ 0 & 0 & s_{n}\end{array}\right]$.

$\mathbf{Y}_{\mathbf{d}}$ represents goods that are produced by local domestic sectors with foreign imported goods excluded. The consumption, investment, and output are considered separately, i.e. the consumption and investment both need adjustment, but export is directly reflected by the final demand, which does not need any adjustment. After eliminating the effect of imported goods on the original input-output table, the carbon emissions of each sector determined by final demand is

$$
\mathbf{F}=\hat{\mathbf{f}}^{\mathbf{d}}\left(\mathbf{I}-\mathbf{A}_{\mathbf{d}}\right)^{-\mathbf{1}} \mathbf{Y}_{\mathbf{d}}
$$

Then the equation for embodied carbon dioxide emission intensity of each sector is:

$$
f=\mathbf{f}^{\mathbf{d}}\left(\mathbf{I}-\mathbf{A}_{\mathbf{d}}\right)^{-\mathbf{1}}
$$

If we diagonalize the direct carbon emissions intensity, the equation above can also be called carbon emissions matrix. By calculating forward linkages and backward linkages, we can also determine the key sectors $(\mathrm{Su}$ and Song, 2010; Chang, 2015). However, this paper will analyze key sectors of carbon emissions from the perspective of elasticity. 


\subsection{The identification of carbon dioxide emission sectors}

For carbon dioxide emissions, different sectors have different effects on reducing carbon emissions. Using the method of elasticity, we can analyze the effects of different sectors on reducing carbon emission are. Normally, sectors with greater elasticity should be restricted since they are more influential in terms of reducing carbon emissions. In this paper, we use the elasticity index to denote the intensity of sectors' carbon emissions. The definition of the elasticity index is shown as below.

$$
\begin{gathered}
\Delta F_{i}=f^{d}\left(I-A_{d}\right)^{-1} \Delta Y_{d i} \\
\varepsilon_{i}=\frac{\Delta F_{i} / F}{\Delta Y_{d i} / Y_{d i}}
\end{gathered}
$$

In the equations, $\varepsilon_{i}$ denotes the carbon emission elasticity of the final output of sector $i$. With this formula, we can derive the sum of percentage $\mathrm{CO}_{2}$ emissions changes of different industries caused by change in sector $i$ 's final demand. The equation above denotes the percentage change of all industries' $\mathrm{CO}_{2}$ emissions, caused by a change of $1 \%$ in sector $i$.

\subsection{Multi-objective model}

\subsubsection{Objective Functions}

In a country's development, its economic development is especially important. Economic growth can raise people's income level and boost the society's development. However, in the process of the development, if we do not value the protection of our environment, then the development may affect the balance between man and nature, and even limit the future development. Therefore, our priority is to make the economic growth as rapid as possible, i.e. we should achieve highest value of Gross Domestic Production (GDP). However, in the process of the development, we cannot merely pursuit economic growth and jeopardize the environment. As a result, our subsidiary goal is to make lowest possible sum of all sectors' carbon emissions. The two goals are presented in formulae as shown below.

$$
\begin{gathered}
\max O_{1}=\sum_{i} Y_{i}=\mathbf{e}^{\prime} \cdot \mathbf{Y} \\
\max O_{2}=\mathbf{f}^{\mathbf{d}}\left(\mathbf{I}-\mathbf{A}_{\mathbf{d}}\right)^{-\mathbf{1}} \cdot \mathbf{Y}
\end{gathered}
$$

Here e denotes summation of column vectors, representing that all the elements are 1 , which can be used in solving the sum of all sectors' final outputs. $O_{1}$ represents the sum of the GDP, and $O_{2}$ represents the sum of all carbon emissions. Our goal is to make highest possible GDP value and lowest carbon emission.

\subsubsection{Constraints}

GDP Constraints: when we attach great importance to environment protection, we cannot afford the cost of deterring economic development. Therefore, in our constraints, total GDP cannot be lower than the planned final output, i.e. the sum of total output of different sectors cannot be lower than the planned GDP. The mathematical form is shown as follows.

$$
\mathbf{e}^{\prime} \mathbf{Y}_{\mathbf{t}} \geq Y_{0}
$$

$Y_{0}$ here denotes planned annual GDP; $Y_{t}$ here denotes the real annual final output vector of different sectors at $t$ th year.

Energy Constraints: In the process of economic development, the total carbon emissions cannot exceed the expected goal. Due to the restriction of availability of data, this paper uses total carbon emissions in 2015 as constraint goal, i.e. after adjustment of structure, total carbon emissions cannot exceed total carbon emissions of 2015. The mathematical relation is shown below:

$$
\mathbf{f}^{\mathbf{d}}\left(\mathbf{I}-\mathbf{A}_{\mathbf{d}}\right)^{-\mathbf{1}} \cdot \mathbf{Y}_{\mathbf{t}} \leq E_{0}
$$

$\mathbf{Y}_{\mathbf{t}}$ here represents the final output vector of different sectors; $E_{0}$ represents planned total carbon emissions. The expression above represents that, with unchanging technology level (constant and unchanged direct consumption coefficient matrix $A$ ), we make adjustments to the final output of different sectors, making the carbon emissions less than the planned total amount.

Industrial structure constraints: based on the magnitude of elasticity, we can determine key sectors in terms of carbon emissions. During programming, we can constrain such key sectors in order to minimize the total carbon emissions of key sectors; meanwhile, we can also determine which sectors have less effect on carbon emissions (low-carbon sectors) and encourage the output of such sectors. The average elasticity of such sectors is

$$
\tilde{\varepsilon}=\frac{\sum \varepsilon_{i}}{n}
$$

The value of key carbon emissions sector is $\frac{\varepsilon_{i}}{\bar{\varepsilon}}>1$; the value of non-key carbon emissions sector is: $\frac{\varepsilon_{i}}{\bar{\varepsilon}} \leq 1$.

As mentioned above, we need to constrain the output of key carbon emissions sectors and encourage the output of non-key (low-carbon) sectors. The constraints can then be expressed as

$$
\frac{\mathbf{e}_{1}^{\prime} \mathbf{Y}_{\mathbf{t}}}{\mathbf{e}^{\prime} \mathbf{Y}_{\mathbf{t}}} \leq w_{1} ; \frac{\mathbf{e}_{2}^{\prime} \mathbf{Y}_{\mathbf{t}}}{\mathbf{e}^{\prime} \mathbf{Y}_{\mathbf{t}}} \geq w_{2}
$$

$\mathbf{e}_{1}$ here denotes column vector; the corresponding element of those constrained sectors is 1 , while the corresponding element of unconstrained sector is $0 . \mathbf{e}_{2}$ here also denotes column vector; the corresponding element of those constrained sectors is 0 , while the corresponding element of unconstrained sector is $1 . w_{1}$ and $w_{2}$ here represent the percentage of the value of products of constrained sectors and the final output of unconstrained sector final in GDP.

Therefore, the multi-objective programming model built in this paper can be expressed as follows.

$$
\begin{gathered}
\min \left(P_{1} d_{1}^{-}+P_{2} d_{2}^{+}\right) \\
\mathbf{e}^{\prime} \mathbf{Y}_{\mathbf{t}}-d_{1}^{+}+d_{1}^{-}=Y_{0} \\
\left\{\begin{array}{c}
\mathbf{f}^{\mathbf{d}}\left(\mathbf{I}-\mathbf{A}_{\mathbf{d}}\right)^{-\mathbf{1}} \cdot \mathbf{Y}_{\mathbf{t}}--d_{2}^{+}+d_{2}^{-}=E_{0} \\
\frac{\mathbf{e}_{1}^{\prime} \mathbf{Y}_{\mathbf{t}}}{\mathbf{e}^{\prime} \mathbf{Y}_{\mathbf{t}}} \leq w_{1} \\
\frac{\mathbf{e}_{2}^{\prime} \mathbf{Y}_{\mathbf{t}}}{\mathbf{e}^{\prime} \mathbf{Y}_{\mathbf{t}}} \geq w_{2} \\
\mathbf{Y}_{\mathbf{t}} \geq 0, d_{i}^{+} \geq 0, d_{i}^{-} \geq 0
\end{array}\right.
\end{gathered}
$$




\section{Identification of key carbon emissions sectors}

\subsection{Direct and embodied carbon intensity}

Here, the direct carbon intensity refers to the direct carbon emissions during the production process of each sector due to the consumption of fossil fuel resources; embodied carbon intensity refers to the carbon emissions during the production process of each sector due to the direct consumption of fossil fuel resource and indirect connection to other sectors (which indirectly leads to the consumption of fossil fuel of other sectors). Therefore, indirect carbon emissions are the difference between embodied carbon emissions and direct carbon emissions (Chen and Bo, 2010). Based on the model we built earlier, we can get the embodied carbon intensity data of 28 sectors in 2015. The result is shown in the following table.

TABLE IV. EMBODIED CARBON INTENSITY DATA OF 28 SECTORS IN 2015

\begin{tabular}{|c|c|c|}
\hline Label & Sector & $\begin{array}{l}\text { Embodied } \\
\text { intensity } \\
\text { (kg/ Yuan) }\end{array}$ \\
\hline 1 & Agriculture, Forestry, Animal Husbandry and Fishery & 0.086557 \\
\hline 2 & Mining and Washing of Coal & 0.482531 \\
\hline 3 & Extraction of Petroleum and Natural Gas & 0.292138 \\
\hline 4 & Mining and Processing of Metal Ores & 0.27815 \\
\hline 5 & Mining of Other Ores & 0.263025 \\
\hline 6 & Manufacture of Foods and tobacco & 0.096327 \\
\hline 7 & Manufacture of Textile & 0.163449 \\
\hline 8 & Manufacture of Leather, Fur, Feather and Related Products and Footwear & 0.120483 \\
\hline 9 & Processing of Timber and manufacture of furniture & 0.161248 \\
\hline 10 & $\begin{array}{l}\text { Manufacture of Paper and Paper Products and manufacture of articles for } \\
\text { culture, education, arts and crafts, sport and entertainment activities }\end{array}$ & 0.223391 \\
\hline 11 & Processing of Petroleum, Coking and Processing of Nuclear Fuel & 0.955928 \\
\hline 12 & Manufacture of Raw Chemical Materials and Chemical Products & 0.342946 \\
\hline 13 & Manufacture of Non-metallic Mineral Products & 0.379935 \\
\hline 14 & Smelting and Pressing of Metals & 0.582713 \\
\hline 15 & Manufacture of Metal Products & 0.33453 \\
\hline 16 & Manufacture of General and Special Purpose Machinery & 0.238611 \\
\hline 17 & $\begin{array}{c}\text { Manufacture of Railway, Ship, Aerospace and Other Transport } \\
\text { Equipments }\end{array}$ & 0.201529 \\
\hline 18 & Manufacture of Electrical Machinery and Apparatus & 0.284536 \\
\hline 19 & $\begin{array}{c}\text { Manufacture of Computers, Communication and } \\
\text { Other Electronic Equipment }\end{array}$ & 0.162117 \\
\hline 20 & Manufacture of Measuring Instruments and Machinery & 0.171411 \\
\hline 21 & Other Manufacture & 0.230857 \\
\hline 22 & Production and Supply of Electric Power and Heat Power & 1.079835 \\
\hline 23 & Production and Supply of Gas & 0.265582 \\
\hline 24 & Production and Supply of Water & 0.249091 \\
\hline 25 & Construction & 0.25225 \\
\hline 26 & Transport, Storage and Post & 0.275609 \\
\hline 27 & Wholesale, Retail Trade and Hotel, Restaurants & 0.063917 \\
\hline 28 & Others & 0.088709 \\
\hline
\end{tabular}

From the table above, we can find that the 22nd sector, Production and Supply of Electric Power and Heat Power, has the highest embodied carbon emissions intensity of $1.08 \mathrm{~kg} \mathrm{CO} \mathrm{CO}_{2}$ emissions for a 1-syuan production. Therefore, the Production and Supply of Electric Power and Heat Power sector should be categorized as highenergy-consuming sector. However, the sector plays an important role in providing the essential electrical and heat energy required by the economic production of other sectors; thus, it consumes more fossil fuel resources. The direct and embodied carbon intensity is shown in the following diagram.

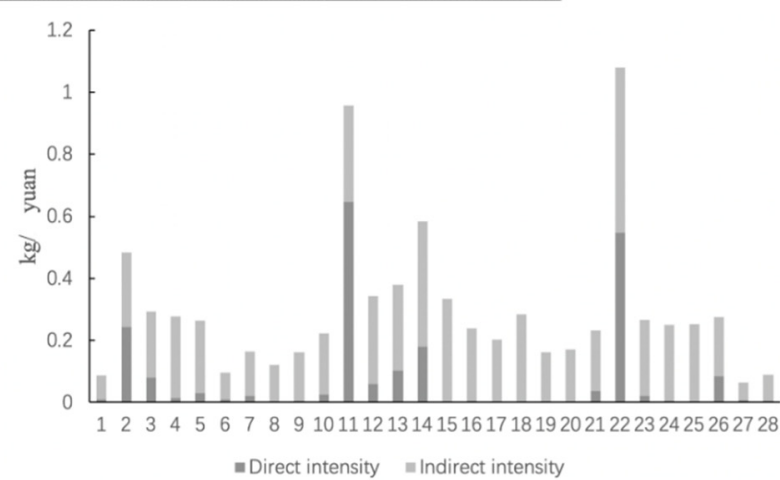

Figure 2. Direct and embodied carbon intensity of different sectors

From the diagram above, we can directly see that direct carbon emissions mainly come from the 2 nd, 11 th, 
14th, and 22nd sector, i.e. Mining and Washing of Coal, Processing of Petroleum, Coking and Processing of Nuclear Fuel, Smelting and Pressing of Metals, and Production and Supply of Electric Power and Heat Power (4 in total). The diagram above well reflects the relations of magnitudes of direct and embodied carbon intensity of different sectors. Many sectors will not directly consume resources, and thus direct carbon intensity (the black part of the diagram) can be neglected. Furthermore, the directed diagram shown below can show the carbon emissions connection between different sectors, and the thickness of the lines connecting them represent the strength of connection between different sectors.

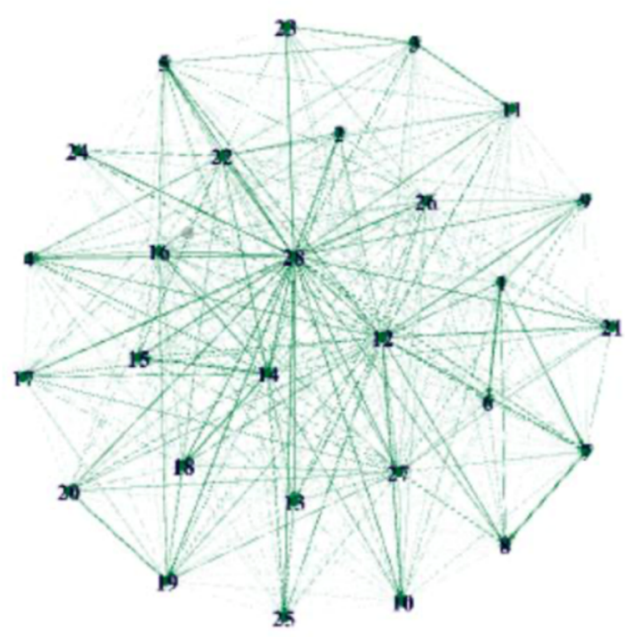

Figure 3. directed diagram showing the connections between different sectors

\subsection{Trend of carbon emissions}

By section 4.1, we can get the mass of $\mathrm{CO}_{2}$ emissions caused by unit total production, or carbon emissions intensity. In order to match the carbon emissions intensity that is frequently used in news reports (which is normally expressed as $\mathrm{CO}_{2}$ emissions of unit GDP), by section 3.2, we calculated the carbon emissions of unit GDP from the year 2002 to 2015 . GDP data of years $2002-2015$ are calculated based on the base year of each year respectively. Because of inflation, we need to convert such nominal GDPs to real GDPs of each year with the base year of 2015 in order to better compare them.

$$
G D P_{t}^{*}=G D P_{t} \times I_{t}
$$

Here $G D P_{t}$ is the nominal GDP of $t$ th year, $I_{t}$ represents the GDP deflator from $t$ th year to the year of 2015. Based on the table of embodied carbon intensity data of 28 sectors in 2015, we multiply it with the real GDPs and nominal GDPs of each sector in the inputoutput table respectively. The resultant data are shown as figure below.

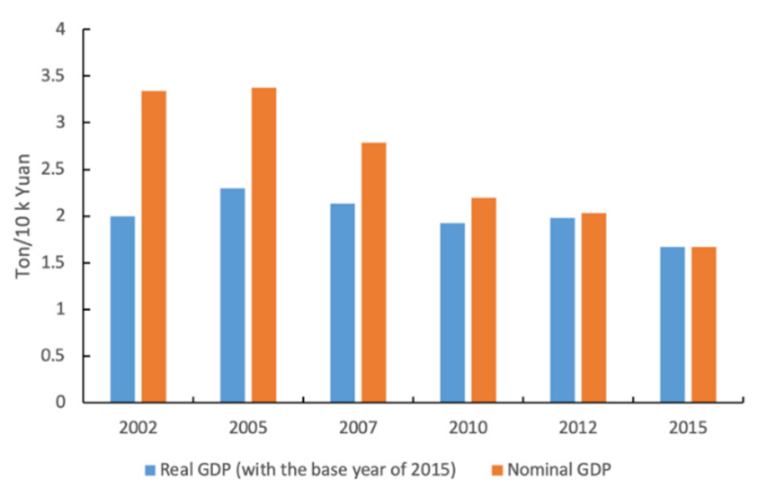

Figure 4. $\quad \mathrm{CO}_{2}$ emissions of unit GDP

The diagram above well reflects the recent carbon emissions of China. First, from the perspective of real GDP (with the base year of 2015), China has relatively lower $\mathrm{CO}_{2}$ emissions per unit GDP before the year of 2002 , reaches its maximum at the year of 2005, and keeps its trend of decreasing after 2005. This indicates that before being part of WTO, Chinese industries are less developed and thus have lower carbon emissions intensity; after being part of WTO, Chinese industries just began its development, and thus have higher carbon emissions intensity. However, as the technologies began developing more and more rapidly, the energy consumption per unit GDP decreases, and accordingly carbon emissions per unit GDP also decreases. From the perspective of nominal GDP (calculated using the price of the respective year), Chinese carbon emissions intensity started to decrease rapidly from the year of 2002 (from 3.34 ton per 10 thousand Chinese yuan in the year of 2002 to 1.67 ton per 10 thousand Chinese yuan in the year of 2015). This indicates that China began to become an energy-saving and emissions-reducing economy, and the economic structures also began to change.

\subsection{Key carbon emissions sectors}

As mentioned in section 3.5, by deriving carbon emissions elasticity index, we can analyze the increased percentage of $\mathrm{CO}_{2}$ emissions of each sector when adding $1 \%$ to the final production. For larger carbon emissions elasticity index, the sector is more influential sector of carbon emissions (a unit increase of output leads to more $\mathrm{CO}_{2}$ emissions); conversely, for lower carbon emissions elasticity index, the sector has a smaller potential (a unit increase of output leads to relatively lower $\mathrm{CO}_{2}$ emissions). Therefore, by restricting sectors with high carbon emissions potential and encouraging low carbon emissions potential sectors, our country's economic structures can be changed and lead to a harmonious development of economy and environment. The carbon emission index of each sector is shown in the following table. 
TABLE V. CARBON EMISSION INDEX OF EACH SECTOR

\begin{tabular}{|c|c|c|}
\hline Sector & elasticity & Ranking \\
\hline 25 & $4.105383^{*}$ & 1 \\
\hline 28 & $1.614091^{*}$ & 2 \\
\hline 16 & $0.747819^{*}$ & 3 \\
\hline 17 & $0.699588^{*}$ & 4 \\
\hline 18 & $0.566057 *$ & 5 \\
\hline 6 & 0.358479 & 6 \\
\hline 14 & 0.33155 & 7 \\
\hline 22 & 0.320528 & 8 \\
\hline 27 & 0.284672 & 9 \\
\hline 8 & 0.260294 & 10 \\
\hline 19 & 0.250421 & 11 \\
\hline 26 & 0.236239 & 12 \\
\hline 15 & 0.217578 & 13 \\
\hline 3 & 0.212752 & 14 \\
\hline 12 & 0.185429 & 15 \\
\hline 10 & 0.174541 & 16 \\
\hline 1 & 0.139982 & 17 \\
\hline 4 & 0.137428 & 18 \\
\hline 11 & 0.121173 & 19 \\
\hline 9 & 0.103722 & 20 \\
\hline 13 & 0.094396 & 21 \\
\hline 7 & 0.089188 & 22 \\
\hline 23 & 0.053014 & 23 \\
\hline 24 & 0.022854 & 24 \\
\hline 21 & 0.021391 & 25 \\
\hline 20 & 0.014831 & 26 \\
\hline 2 & 0.005664 & 27 \\
\hline 5 & 0.005603 & 28 \\
\hline
\end{tabular}

one. The results below include two cases, which are the

From the table above, we can find that Construction sector has the highest carbon emissions elasticity index of 4.105383 , i.e. when the final demand of Construction sector increases $1 \%$, it leads to an increase of $4.105383 \%$ overall total $\mathrm{CO}_{2}$ emissions; it means that Construction is the key sector in terms of carbon emissions in our country: to decrease the carbon emissions, we need to decrease the percentage of Construction sector in our country's industrial sectors. Besides, sectors such as Others, Manufacture of General and Special Purpose Machinery, Manufacture of Railway, Ship, Aerospace and Other Transport Equipment, and Manufacture of Electrical Machinery and Apparatus also have high carbon emissions elasticity indexes of 1.614091, 0.747819 , 0.699588, and 0.566057 respectively, indicating that when the final demand of Construction sector increases $1 \%$, it leads to an increase of $1.614091 \%, 0.747819 \%, 0.699588 \%$, and $0.566057 \%$ over-all total $\mathrm{CO}_{2}$ emissions respectively. These sectors' carbon emissions elasticity indexes are higher than the average value, which provide us with basis of controlling the structures of these sectors.

\section{Results}

Based on the status quo of Chinese economic development and carbon emissions, it is reasonable to set the new goal of carbon emissions as $95 \%$ of the present economic structure when there is $0 \%$ and $5 \%$ of GDP growth.

First, with the goal of reducing carbon emissions as $95 \%$ of the present one (which is 11011.3 million ton) but with constant unchanged GDP (0 GDP growth), the resultant economic structure is shown as below.

TABLE VI. RESULTANT ECONOMIC STRUCTURE WITH 95\% OF THE PRESENT CARBON EMISSIONS AMOUNT AND CONSTANT UNCHANGED GDP

\begin{tabular}{|c|c|c|c|}
\hline Sector & Real GDP value in 2015/10K Yuan & Programmed GDP value/10K Yuan & Change \\
\hline 3 & -84411350.05 & -94197798.99 & 0.115938 \\
\hline 16 & 363263045.7 & 361871490.6 & -0.003831 \\
\hline 17 & 402365468.4 & 406789638.3 & 0.010995 \\
\hline 18 & 230588978.6 & 221994857 & -0.03727 \\
\hline 19 & 179042900.8 & 189648152.1 & 0.059233 \\
\hline 23 & 23136824.08 & 17515339.79 & -0.242967 \\
\hline 24 & 10634384.07 & 7599204.499 & -0.285412 \\
\hline 25 & 1886419715 & 1882889149 & -0.001872 \\
\hline 28 & 2108989325 & 2131107352 & 0.010488 \\
\hline
\end{tabular}

The real GDP value in 2015 and programmed GDP values of different sectors are also shown in the following diagram. 


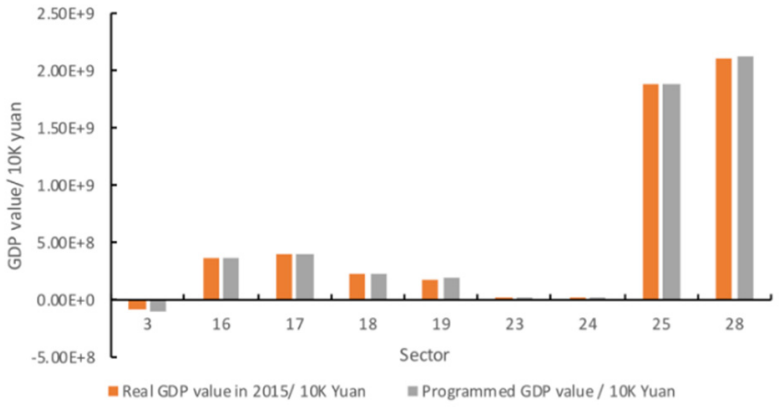

Figure 5. resultant economic structure with $95 \%$ of the present carbon emissions amount and constant unchanged GDP
Key carbon emissions sectors, such as Construction, Manufacture of General and Special Purpose Machinery, Manufacture of Railway, Ship, Aerospace and Other Transport Equipments, and Manufacture of Electrical Machinery and Apparatus, has changes of $-0.19 \%,-0.38 \%,+1.09 \%$, and $-3.73 \%$ respectively. Also, the sector Manufacture of Computers, Communication, and Other Electronic Equipment has a change of $+5.92 \%$.

Second, with the goal of reducing carbon emissions as $95 \%$ of the present one (which is 11011.3 million ton) but with 5\% GDP growth, the resultant economic structure is shown as below.

TABLE VII. RESULTANT ECONOMIC STRUCTURE WITH 95\% OF THE PRESENT CARBON EMISSIONS AMOUNT AND 5\% GDP GROWTH

\begin{tabular}{|c|c|c|c|}
\hline Sector & Real GDP value in 2015/10K Yuan & Programmed GDP value / 10K Yuan & Change \\
\hline 7 & 63246891.08 & 109581321.1 & 0.732596167 \\
\hline 8 & 250411766.3 & 331443735.1 & 0.323594893 \\
\hline 9 & 74557322 & 122668597 & 0.645292424 \\
\hline 16 & 363263045.7 & 348899677.7 & -0.039539855 \\
\hline 17 & 402365468.4 & 417948132 & 0.038727637 \\
\hline 18 & 230588978.6 & 179138526.5 & -0.223126241 \\
\hline 19 & 179042900.8 & 226452870.5 & 0.264796702 \\
\hline 25 & 1886419715 & 1861042266 & -0.013452705 \\
\hline 28 & 2108989325 & 2215680288 & 0.050588669 \\
\hline
\end{tabular}

The real GDP value in 2015 and programmed GDP values of different sectors are also shown in the following diagram.

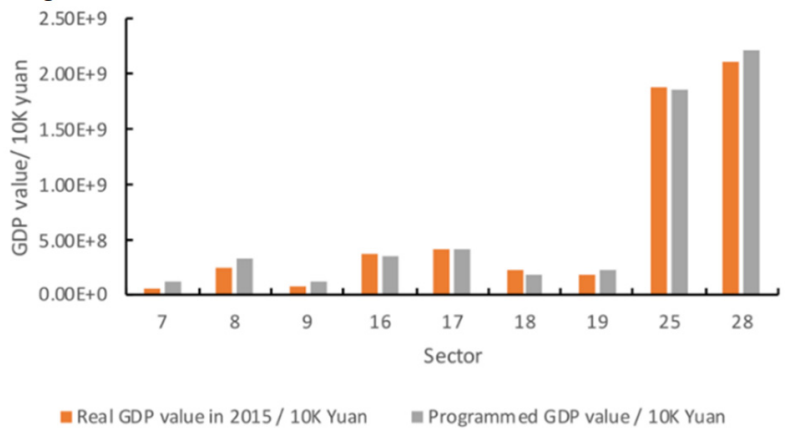

Figure 6. resultant economic structure with $95 \%$ of the present carbon emissions amount and 5\% GDP growth

Key carbon emissions sectors, such as Construction, Manufacture of General and Special Purpose Machinery, Manufacture of Railway, Ship, Aerospace and Other Transport Equipments, and Manufacture of Electrical Machinery and Apparatus, has changes of $-1.3 \%,-3.95 \%,+3.8 \%$, and $-22.3 \%$ respectively. Also, the sector Manufacture of Computers, Communication, and Other Electronic Equipment has a change of $+26.5 \%$.

Although some of key carbon emissions sectors have minor decreases or upticks, the overall percentage of key carbon emissions sectors still decreases. The reason that might account for this is that the sector plays a key role in the country's economic development (mentioned in section 3.6.2, GDP constraints), and we need to take into account the two factors at the same time; over-decreasing will deter the country's economic development.

\section{Conclusions and discussions}

After the research, several conclusions can be reached. First, as shown in the section 4.2, the future trend of Chinese $\mathrm{CO}_{2}$ emissions is elating. Carbon emissions per unit real GDP decreases; carbon emissions per unit nominal GDP also decreases.

Second, as shown in the section of 4.3, the key sectors of carbon emissions are constructions, others, manufacture of general and special purpose machinery, manufacture of railway, ship, aerospace and other transport equipments, and manufacture of electrical machinery and apparatus (listed in the order of decreasing potential of carbon emissions), which is based on the analysis of carbon emissions elasticity index. In order to reach a harmonious development between environment and economy, sectors with high carbon emissions potential should be restricted, and low carbon remissions potential sectors should be encouraged.

Third, as shown in section 5, with the assurance of present economic scale and growth, Chinese carbon emissions amount can be reduced by 580 million ton. Because of the contradictoriness of economic growth and reduction of carbon emissions, by adjusting the industrial structure of the economy, the emissions of $\mathrm{CO}_{2}$ can be reduced 580 million ton. Based on the results of multi- 
objective model, with constant GDP value, if Construction sector's final demand decreases $0.19 \%$, Others sectors increase $1.05 \%$, etc., we can reach the goal of $5 \%$ reduction on carbon emissions. If GDP value has a $5 \%$ growth, then we can meet the goal of $5 \%$ reduction of $\mathrm{CO}_{2}$ with a $1.35 \%$ decrease of Construction sector's final demand and a $5.06 \%$ increase in the final demand of Others sector (with a 5\% GDP growth). Therefore, from the results of multi-objective programming, we can deduce that, by changing the industrial structure, we can achieve the goal of steady economic growth while reducing the carbon emissions. Therefore, China still has a huge potential of reducing carbon emissions.

\section{References}

1. Ang, B. (1995). Multilevel decomposition of industrial energy consumption. Energy Economics, 17(1), pp.39-51.

2. Itoh, Y. and Nakata, T. (2004). Input-Output Analysis for Installing Renewable Energy Systems. Energy \& Environment, 15(2), pp.271-281.
3. Miller, R. (1966). Interregional feedback effects in input-output models: Some preliminary results. Papers of the Regional Science Association, 17(1), pp.105-125.

4. Barna, T. and Leontief, W. (1971). Input-Output Economics. Econometrica, 39(1), p.188.

5. Leontief, W. (1974). Environmental Repercussions and the Economic Structure: An Input-Output Approach: A Reply. The Review of Economics and Statistics, 56(1), p.109.

6. Miller, R. and Blair, P. (2014). Input-output analysis. New York: Cambridge University Press.

7. Chang, N. (2015). Changing industrial structure to reduce carbon dioxide emissions: a Chinese application. Journal of Cleaner Production, 103, pp.40-48.

8. Su Y., Song, S. (2013). Recognition of key sectors in China's $\mathrm{CO}_{2}$ emissions from energy consumption and emission-reduction measures. Statistics \& Information Forum, 28(4), pp. 18-23. 